\title{
A REGULARIZAÇÃO FUNDIÁRIA COMO INSTRUMENTO DE INCLUSÃO SOCIAL E DE SUPERAÇÃO DA POBREZA: ESTUDO DE CASO DA COMARCA DE SÃO JOÃO DA PONTE EM MINAS GERAIS
}

\author{
THE LAND REGULARIZATION AS SOCIAL INCLUSION OF INSTRUMENT AND \\ OVERCOMING POVERTY: CASE STUDY OF SÃO JOÃO DA PONTE IN MINAS \\ GERAIS
}

\author{
${ }^{1}$ Ana Caroline Santos Ceolin
}

\section{RESUMO}

O presente estudo tem por objetivo demonstrar o potencial transformador da regularização fundiária, como importante instrumento de inclusão social e de superação da pobreza, a partir do estudo de caso da Comarca de São João da Ponte situada na região norte do Estado de Minas Gerais e composta por quatro municípios com grande extensão territorial. Por meio de dados levantados junto à Serventia extrajudicial de Registro de Imóveis, será demonstrada a generalizada irregularidade imobiliária da referida Comarca e o seu impacto negativo na economia local, no exercício de direitos urbanísticos de natureza coletiva e individuais pertinentes à titularidade dos imóveis. Com a análise da legislação brasileira que trata do tema, será possível verificar a aplicação prática dos instrumentos legais que visam à regularização fundiária e quais são os avanços obtidos e as possibilidades existentes com a recente regulamentação da usucapião extrajudicial. Novas perspectivas se abrem pela previsão legal da usucapião que tramitará diretamente nos Registros de Imóveis, no sentido de tornar ainda mais viável a formalização de situações fáticas de apreensão física sobre a coisa. Com isso, alargam-se as oportunidades de legalização dos imóveis situados nos Municípios da Comarca de São João da Ponte, o que beneficiará a estrutura urbanística das cidades e a economia local. Tais benefícios são possíveis na medida em que a regularização fundiária se destaca como relevante mecanismo para implementação de políticas urbanísticas e de acesso ao crédito à população, de sorte a se promover a inclusão social e econômica dos indivíduos como meio de superação da pobreza.

Palavras-chave: Estudo de caso, Comarca de são joão da ponte, Regularização fundiária, Usucapião extrajudicial, Políticas urbanísticas, Políticas de acesso ao crédito

\footnotetext{
${ }^{1}$ Mestre em Direito pela Universidade Federal de Minas Gerais - UFMG, Minas Gerais (Brasil). Professora de Direito Civil pela Universidade FUMEC - FUMEC, Minas Gerais (Brasil). E-mail: anacarolineceolin@gmail.com
} 


\begin{abstract}
This study aims to demonstrate the transformative potential of land regularization, as an important instrument of social inclusion and overcoming poverty, from the case study of the District of São João da Ponte located in the northern region of Minas Gerais and consists of four municipalities with large territory. Through data collected by the extrajudicial Usefulness of Real Estate Registry, widespread property irregularity of that judicial district and its negative impact on the local economy will be demonstrated in the exercise of urban rights of collective and individual nature relevant to the ownership of real estate. By the analysis of the brazilian legislation that deals with it, it can be verified the pratical application of legal instruments aimed at regularization and what are the advances made and the possibilities with the recent regulation of extrajudicial prescription. New perspectives open by the legal provision of prescription that processing directly on Property Records, to make it more feasible to formalize factual situations of physical apprehension about the thing. Thus, the legalization opportunities flare of immovable property in the municipalities of the District of São João da Ponte, which will benefit the urban structure of cities and the local economy. These benefits are possible to the extent that land tenure stands out as an important mechanism for implementation of urban policies and access to credit population, so to promote social and economic inclusion of individuals as a means of overcoming poverty.
\end{abstract}

Keywords: Case study of são joão da ponte, Regularization, Extrajudicial adverse possession, Urbanistic policies, Access to credit policies

“... a paz duradoura não pode ser atingida a menos que grandes grupos da população encontrem formas de sair da pobreza” Muhammad Yunus - o banqueiro dos pobres 


\section{INTRODUÇÃO}

Por meio da presente pesquisa pretende-se demonstrar a importância da regularização fundiária como instrumento de inclusão social e superação da pobreza, a partir do estudo de caso da Comarca de São João da Ponte que se localiza na região norte do Estado de Minas Gerais.

Conforme pesquisa desenvolvida sobre o desenvolvimento regional no norte do Estado de Minas Gerais, essa região, que pertence "ao Polígono das Secas, apresentando características físico-climáticas semelhantes às do semiárido nordestino", é marcada pelo subdesenvolvimento econômico e social (SANTOS, SILVA, 2015, p. 8). O subdesenvolvimento da região, ainda de acordo com a pesquisa, pode ser explicado pelo "processo de ocupação sustentado pela pecuária extensiva", que "se caracterizava "pela dispersão espacial dos produtores rurais e sua total dependência em relação aos proprietários de terras", e "pela rígida hierarquia social e o autoritarismo da classe dirigente" (SANTOS, SILVA, 2015, p. 8).

A Comarca de São João da Ponte, localizada a uma distância de $136 \mathrm{~km}$ do município de Montes Claros e composta por quatro municípios - São João da Ponte, Varzelândia, Ibiracatu e Lontra -, pode ser apontada como retrato da região do norte do Estado de Minas Gerais, uma vez que sua economia é baseada predominantemente na agricultura e pecuária ${ }^{1}$.

\footnotetext{
${ }^{1}$ Informações disponíveis no site do IBGE: 〈http://www.cidades.ibge.gov.br>. Acesso no dia 12 de agosto de 2015.
} 
Juntos os municípios que integram a Comarca, objeto do presente estudo, totalizam área de 3.278,383 km² de território e população de 60.732 habitantes (dados apurados por pesquisa de 2014 do IBGE). Um dos aspectos que revela o seu subdesenvolvimento econômico é a generalizada irregularidade imobiliária. Os imóveis situados na Comarca são basicamente irregulares, sendo que, em um total de trinta e dois bairros apenas, apenas sete encontram-se regularizados.

A partir da análise de dados levantados na Serventia extrajudicial de Registro de Imóveis e de demandas individuais pela regularização de imóveis que, frequentemente, acabam se frustrando, verificou-se a necessidade de se enfrentar o tema da regularização fundiária e o seu impacto na economia da Comarca de São João da Ponte com a possibilidade de inclusão social por meio de políticas de acesso ao crédito em condições mais favoráveis à população.

As situações de generalizada irregularidade fundiária na Comarca de São João da Ponte são responsáveis por incontáveis prejuízos à estrutura urbanística das cidades que a integram, para a economia local e, sobretudo, para seus cidadãos que permanecem às margens da legalidade. Não raramente, pessoas bem intencionadas são ludibriadas com falsos títulos de propriedade; pessoas adquirem casa própria confiando na possibilidade de obter financiamento junto às instituições financeiras para construírem suas residências e se deparam com os meandros da irregularidade e clandestinidade imobiliária.

São incontáveis e incalculáveis os reflexos negativos da irregularidade fundiária, não só para a Comarca de São João da Ponte, como de resto para todo o país, que vão desde a insegurança na negociação dos imóveis até a obstrução do exercício pleno e efetivo da cidadania pelos seus titulares que são mantidos às margens do sistema registral brasileiro. A irregularidade, cujos sinônimos são os termos ilegalidade e ilicitude, gera a ideia de caos, de incertezas, fomentando sentimentos de descrença e de impunidade. Além disso, a generalizada irregularidade imobiliária inviabiliza a implementação de políticas habitacionais coesas e profícuas, o que dificulta o pleno gozo do direito a moradia, alçado ao status de direito fundamental na Carta Magna de 1988.

Para a economia da região do norte de Minas Gerais, como no caso da Comarca de São João da Ponte, não é menor a perniciosidade da irregularidade imobiliária. E não é para menos, já que dois dos maiores fatores de instabilidade da economia brasileira, que afugentam investidores nacionais e estrangeiros, consistem na falta de segurança jurídica e nos juros altos (PRESTES, 2013). Boa parte dessa insegurança jurídica advém exatamente da fragilidade do sistema registral e da generalizada clandestinidade imobiliária no país 
(RODRIGUES, 2015). Como conceder crédito a juros baixos sem que seu tomador possa oferecer algum imóvel em garantia? Como estimular políticas de acesso ao crédito em condições mais favoráveis aos indivíduos, se nos casos de inadimplência não se pode contar com um sistema registral eficiente e que impeça, efetivamente, a ocorrência de fraudes e simulações? Como estender o crédito a indivíduos que compõem a camada da população economicamente menos favorecida e que ostentam a pecha de meros posseiros em relação a imóveis adquiridos legitimamente por eles, não obstante?

Como seria se todas as residências da Comarca de São João da Ponte passassem a constar do sistema registral e dos cadastros imobiliários de suas respectivas Prefeituras? Quais benefícios poderão advir de um amplo trabalho de identificação das áreas irregulares e do mapeamento de seus problemas de infraestrutura urbanística? Quais benefícios poderão advir para seus moradores que passarão a portar título de propriedade de seus imóveis?

O que se pretende com o presente artigo é enfrentar esses questionamentos e problemas decorrentes da irregularidade generalizada na Comarca de São João da Ponte, por meio da análise da legislação brasileira que trata da regularização fundiária. Nesse contexto, o estudo da Lei no 11.977 de 07 de julho de 2009, denominada Lei do Programa Minha Casa, Minha Vida, e dos mecanismos jurídicos disciplinados em seu corpo normativo permitirá a identificação de instrumentos que viabilizam a regularização dos imóveis em termos práticos. O estudo da Lei n. 11.977/09 será conjugado com a análise da usucapião extrajudicial que foi recentemente disciplinada pela Lei n. 13.105 de 16 de março de 2015, o novo Código de Processo Civil.

Por fim, será realizada a análise da estreita relação entre a regularização fundiária e a erradicação da pobreza, fazendo-se a seguinte indagação: em que medida a regularização dos imóveis contribuiria para se impulsionar a economia dos municípios da Comarca de São João da Ponte? Essa temática será abordada, considerando-se dois aspectos da regularização enquanto importante e essencial instrumento: a) de identificação das áreas irregulares e da falta de infraestrutura urbanística; e b) de inclusão social e econômica, na medida em que viabiliza a concretização de políticas de acesso ao crédito à população.

\section{2 - A GENERALIZADA IRREGULARIDADE IMOBILIÁRIA NA COMARCA DE SÃO JOÃO DA PONTE}

A Constituição Federal de 1988, no art. 3º, traçou como objetivos da República Federativa do Brasil a erradicação da pobreza e da marginalização e a redução das 
desigualdades sociais e regionais, estabelecendo como princípio fundamental do Estado Democrático brasileiro o princípio da dignidade da pessoa humana.

A redução das desigualdades sociais e regionais constitui objetivo nacional e, em especial, verdadeiro desafio para o Estado de Minas Gerais que é apontado por estudos sociológicos e econômicos como "um dos estados que mais se destaca pelas disparidades regionais", no qual coexistem "regiões dinâmicas e modernas em contraste com regiões atrasadas e estagnadas", como o norte do Estado (SIMÃO, 2004, p. XIV).

Sobre as disparidades econômicas e sociais entre as regiões do Estado de Minas Gerais, foi realizada em 2011 uma pesquisa que aponta o seguinte:

[...] Ainda hoje, os indicadores econômicos e sociais estratificados por região confirmam uma enorme discrepância entre as regiões Central e o Triângulo mineiro, em contraposição ao norte de Minas e os Vales Jequitinhonha e Mucuri.

As intervenções do Estado propiciaram um desenvolvimento econômico concentrador e desigual no Norte de Minas Gerais. A persistência das desigualdades regionais é um grande desafio. Vislumbra-se atualmente um novo ciclo de desenvolvimento no norte de Minas. Projetos como da exploração de minério de ferro na microrregião do Alto Rio Pardo, a exploração de gás mineral na bacia do Rio São Francisco e do novo ciclo de industrialização na microrregião de Montes Claros ensejam um desenvolvimento baseado em investimentos da iniciativa privada, portanto, mais sólido que os ciclos anteriores. No entanto, estes ainda estão em fase de implantação. (SANTOS, SILVA, 2012, p. 21)

Essa disparidade entre as regiões do Estado de Minas Gerais pode ser constatada, inclusive, levando-se em conta o problema da informalidade e irregularidade dos imóveis que, longe de erradicar, acaba por fomentar a pobreza. A generalizada irregularidade em que se encontram os imóveis localizados nos municípios da região do norte de Minas, como no caso da Comarca de São João da Ponte, agrava o problema crônico das moradias as quais, em muitos casos, não são providas de equipamentos urbanos básicos, como saneamento, energia elétrica, e pavimentação por exemplo. A irregularidade imobiliária, neste sentido, acaba ainda por obstar a implementação de políticas econômicas e sociais inclusivas, por efeito cascata.

É certo que a irregularidade fundiária é um problema que assola todo o território do Estado de Minas Gerais, como também significativa e considerável parte do território brasileiro (FERNANDES, 2001). Porém, confrontando dados de Serventias de Registro de Imóveis situadas em diferentes regiões do Estado, é possível constatar que no norte de Minas o problema é grave, sério e urgente. 
Tomando como exemplo dados da Serventia de Registro de Imóveis da Comarca de São João da Ponte que é composta por quatro Municípios - São João da Ponte, Varzelândia, Ibiracatu e Lontra - com população total de aproximadamente 60.732 habitantes e território de 3.278,383 km², em comparação com a Comarca de Galiléia com 7.076 habitantes e território de 720,355 km², situada na região sul do Estado de Minas Gerais (dados apurados por pesquisa de 2014 do IBGE), pode-se verificar o que se segue:

Segundo declarações publicadas no site da Corregedoria Nacional de Justiça, as Serventias de Imóveis de São João da Ponte e de Galiléia arrecadaram basicamente o mesmo valor a título de emolumentos no ano de $2014^{2}$. Ou seja, o Registro de Imóveis da Comarca do norte de Minas Gerais, cuja população é oito vezes maior e o território cinco vezes maior do que os da Comarca de Galiléia, situada na região leste do Estado, arrecada igual ou menos do que a Serventia de São João da Ponte. No que se refere ao número de matrículas, também impressiona o fato de que a Comarca de São João da Ponte possui apenas 6250 matrículas, já a Comarca de Galiléia conta com total de 5236 matrículas.

Outro reflexo negativo da generalizada informalidade refere-se à baixa arrecadação tributária no que diz respeito a impostos municipais, como imposto territorial urbano - IPTU - e o imposto de transmissão de bens imóveis inter vivos - ITBI. Tomando-se como exemplo apenas a arrecadação de IPTU pelo Município de São João da Ponte, no exercício financeiro do ano de 2014, foi recolhido o montante total de apenas $\mathrm{R} \$ 19.913,23$ (dezenove mil e novecentos e treze reais e vinte e três centavos), conforme declaração expedida pelo Setor de Tributação da Prefeitura Municipal de São João da Ponte.

Devido à baixa arrecadação a título de impostos como IPTU e ITBI, os municípios da Comarca de São João da Ponte permanecem na dependência em relação a recursos provindos da União ou do Estado para capacitar suas políticas sociais.

Também no que diz respeito ao repasse de verbas federais ou estaduais para os municípios, a irregularidade fundiária acaba afetando prejudicialmente. Em 2014, as Prefeituras de São João da Ponte e de Varzelândia perderam verbas federais por falta de registro de terrenos que viabilizasse a construção de escolas e postos de saúde, e também de poços artesanais.

Em termos individuais, a falta de regularização de imóveis afeta diretamente o interesse de várias pessoas que, munidas de recibos e de documentos diversos, procuram a Serventia de Imóveis com objetivo de regularizarem seus imóveis e acabam impossibilitadas

\footnotetext{
${ }^{2}$ Informações do site da Corregedoria Nacional de Justiça: < http://cnj.jus.br>. Acesso no dia 12 de agosto de 2015 .
} 
de fazê-lo. Os interesses de instituições financeiras ficam igualmente prejudicados, na medida em que procuram, muitas vezes, em vão auxiliar na regularização de títulos informais de seus clientes, para fins de lhes conceder crédito mediante garantia real.

Por alto, pode-se dizer otimistamente que apenas $20 \%$ (vinte por cento) de todos os imóveis da Comarca de São João da Ponte possuem matrícula na Serventia de Registro de Imóveis. A cidade de São João da Ponte totaliza dezessete bairros, desses, apenas cinco encontram-se em situação regular; e todos os cinco distritos do município também são irregulares.

Os Municípios de Ibiracatu e de Lontra, por sua vez, simplesmente não possuem registro de qualquer loteamento, ou bairro, no Registro de Imóveis. Os imóveis urbanos da cidade de Ibiracatu simplesmente não são registráveis, dada a ausência de matrícula referente à área urbana do município. Em Lontra, apenas o centro da cidade é registrável por ser área de propriedade da Mitra Arquidiocesana de Montes Claros que transfere para os moradores o título de propriedade, por meio de escritura pública de compra e venda, mediante pagamento de valor a ser ajustado em cada caso com o adquirente.

Essa generalizada irregularidade imobiliária dos quatro municípios e distritos da Comarca de São João da Ponte pode ser atribuída a fatores de natureza histórica e cultural: as áreas e bairros eram fazendas de enorme extensão territorial, cujos proprietários eram grandes latifundiários da região (SANTOS, SILVA, 2011, p. 5). Com o falecimento desses proprietários, essas terras foram divididas entre seus herdeiros que, por sua vez, cediam a terceiros seus direitos hereditários, sem qualquer preocupação de cunho formal. Com isso, criou-se a cultura do informalismo que foi reforçada pela generalizada falta de conhecimento populacional da importância de se registrar os imóveis. Até nos dias atuais, é frequente e comum a prática de se negociar imóveis por meio de mera cessão de direito ou por contratos particulares, e até mesmo por simples recibos de pagamento.

Como se pretende demonstrar no presente estudo, a cultura do informalismo nas transações imobiliárias é agravada pela falta de interesse político municipal na Comarca de São João da Ponte em enfrentar tal problema e, sobretudo, pela falta de conhecimento da população em geral quanto à importância da regularização dos imóveis.

Diante desses dados, é imprescindível traçar a estreita relação entre a regularização fundiária e a erradicação da pobreza, fazendo-se a seguinte indagação: em que medida a regularização dos imóveis contribuiria para se impulsionar a economia dos municípios da Comarca de São João da Ponte? 
Em resposta a esse questionamento, podem ser destacados dois aspectos da regularização enquanto importante e essencial instrumento: a) de identificação das áreas irregulares e da falta de infraestrutura urbanística; e b) de inclusão social e econômica, na medida em que viabiliza a concretização de políticas de acesso ao crédito à população.

Porém, antes dessa análise, é preciso proceder a detido estudo da legislação brasileira pertinente à regularização de imóveis, para se conhecer os mecanismos legais que viabilizam a sua aplicação prática e as possibilidades existentes com a recente regularização da usucapião extrajudicial, como se passa a demonstrar.

\section{3 - A REGULARIZAÇÃO FUNDIÁRIA NA LEGISLAÇÃO BRASILEIRA E SUA APLICAÇÃo PRÁTICA}

Desde o advento da Constituição Federal de 1988, o legislador ordinário vem editando leis com o claro objetivo de estabelecer medidas, práticas e concretas, que possibilitem aos Municípios a legalização de imóveis situados em seu perímetro urbano principalmente.

Devido a sua enorme importância para o desenvolvimento de políticas urbanas voltadas para o objetivo de garantir moradia digna às pessoas, a regularização fundiária tem sido objeto de inúmeras leis promulgadas recentemente no Brasil. Leis, como o Estatuto da Cidade - Lei n. 10.257/01, a Lei do Programa Minha Casa, Minha Vida - Lei n. 11.977/09, e a Lei n. 12.424/11 que trata do registro da regularização fundiária urbana e que acrescentou dispositivos à Lei de Registros Públicos - Lei n. 6.015/73, dotaram os Municípios de instrumentos hábeis à concretização da meta de regularizar imóveis neles situados. Com base nessas leis, o desembargador do Tribunal de Justiça de São Paulo Kioitsi Chicuta destacou o objetivo da política de desenvolvimento urbano a ser instituída pelo Poder Público municipal:

A política de desenvolvimento urbano, executada pelo Poder Público municipal, conforme diretrizes gerais fixadas em lei, tem por objetivo ordenar o pleno desenvolvimento das funções sociais da cidade e garantir o bem estar de seus habitantes. (2000)

O art. 46 da Lei n. 11.977 de 07 de julho de 2009, que dispõe sobre o Programa Minha Casa, Minha Vida - PMCMV e a regularização fundiária de assentamentos localizados em áreas urbanas, define a regularização como o "conjunto de medidas jurídicas, urbanísticas, ambientais e sociais que visam à regularização de assentamentos irregulares e à titulação de 
seus ocupantes, de modo a garantir o direito social à moradia, o pleno desenvolvimento das funções sociais da propriedade urbana e o direito ao meio ambiente ecologicamente equilibrado".

O art. 47, inciso VI, da Lei Minha Casa, Minha Vida, considera assentamentos irregulares "aquelas ocupações inseridas em parcelamentos informais ou irregulares, localizadas em áreas urbanas públicas ou privadas, utilizadas predominantemente para fins de moradia".

Conforme se extrai dos dispositivos legais, a regularização fundiária tem, a um só tempo, o objetivo de legalizar terrenos urbanos ocupados por várias pessoas por meio de medidas sociojurídicas e de atribuir e garantir a titularidade dos imóveis regularizados aos seus ocupantes.

Em âmbito coletivo, a regularização visa a organizar áreas informais que foram, na maioria dos casos, ocupadas desordenadamente para fins de moradia, empregando políticas de desenvolvimento urbano. As medidas a serem aplicadas com o intuito de legalizar os assentamentos urbanos irregulares devem conjugar fatores urbanísticos, ambientais e sociais, que sejam condizentes com a realidade de cada município ou região a ser levada em conta pelas autoridades públicas nos projetos a serem desenvolvidos. Esse viés social da regularização fundiária pode ser efetivado pela inserção de equipamentos de infraestrutura urbana previstos no art. 47 da Lei n. 11.977/09, tais como drenagem de águas pluviais urbanas, esgotamento sanitário, abastecimento de água potável, distribuição de energia elétrica e limpeza urbana, coleta e manejo de resíduos sólidos.

Nesse contexto, a Lei n. 11.977/09 previu o importante instrumento da demarcação urbanística que consiste em procedimento administrativo pelo qual se "demarca imóvel de domínio público ou privado, definindo seus limites, área, localização e confrontantes, com a finalidade de identificar seus ocupantes e qualificar a natureza e o tempo das respectivas posses", conforme preceitua o inciso III do seu art. 47.

Já sob o aspecto privado, a regularização fundiária alcança perspectivas individuais, na medida em que propicia aos moradores de cada imóvel a respectiva titularidade por meio da legitimação de posse que, nos termos do inciso IV do art. 47 da Lei Minha Casa, Minha Vida, consiste: "no ato do poder público destinado a conferir titulo de reconhecimento de posse de imóvel objeto de demarcação urbanística, com a identificação do ocupante e do tempo e natureza da posse".

Posteriormente, o título de legitimação de posse poderá ser convertido, pelo oficial de registro de imóveis e a requerimento de seu detentor, em registro de propriedade, conforme 
dispõe o art. 60 da Lei n. 11.977/09. Para que ocorra tal conversão em propriedade o citado dispositivo legal estabelece o prazo de cinco anos a contar do registro do título de legitimação de posse na Serventia de Registro de Imóveis.

Sobre o instituto jurídico da regularização fundiária instituído pela lei em comento, é importante destacar as palavras do desembargador Marcelo Rodrigues do Tribunal de Justiça de Minas Gerais que vem se dedicando com afinco aos estudos dos serviços extrajudiciais:

\begin{abstract}
A regularização fundiária de interesse social foi o instituto jurídico mais inovador e revolucionário até então criado como instrumento de regularização imobiliária no país. Consistiu em profunda mudança política no mundo tradicional de administração urbanística das cidades brasileiras que, num passado recente, consistia na remoção (ou expulsão) dessas populações no local em que se deu a ocupação. Visando a solucionar os graves problemas urbanísticos, ambientais e sociais a serem enfrentados no âmbito do reordenamento urbano das cidades brasileiras, essa modalidade de regularização fundiária tem o mérito jde harmonizar ações de diferentes órgãos do Poder Público, do Registro Imobiliário e das organizações representativas da sociedade civil para o êxito da regularização fundiária. (2015)
\end{abstract}

A despeito de seus inquestionáveis avanços e préstimos à regularização fundiária, a dificuldade que se esbarra para aplicação prática da Lei n. 11.977/09 em alguns Municípios, como os que integram a Comarca de São João da Ponte, é a falta de interesse e de planejamento político local.

Em 2001, Jupira Gomes de Mendonça ressaltou avanços de alguns municípios brasileiros e a dificuldade da maioria deles na criação de programas de gestão pública, tendo em vista as exigências constitucionais de ordenação da cidade expressas no plano diretor:

Se a nova abordagem de Plano Diretor e legislação urbanística tem significado avanço no que diz respeito à gestão urbana, esta, entretanto, não é a realidade da maioria dos municípios brasileiros. A autonomia municipal conquistada no processo constituinte trouxe também alguns limites à gestão pública, na forma como tem sido praticada. Faz-se importante, pois, discutir alternativas para que os avanços na legislação urbanística, que têm sido efetivamente alcançados em alguns municípios, possam ser difundidos. (2001, p. 156)

Na Comarca de São João da Ponte, foram realizadas várias reuniões entre a titular da Serventia de Registro de Imóveis com Prefeitos, Secretários Municipais e também nas Câmaras dos Vereadores dos quatro municípios, mas pouco ou nada se caminhou ${ }^{3}$. 
Entre as razões apontadas pelas Prefeituras Municipais e por alguns Vereadores para não se implementar a regularização fundiária estão a falta de verbas e recursos financeiros para medição das áreas e lotes a serem regularizados, a intenção de não se indispor com loteadores irregulares, e o receio de desagradar titulares de imóveis que poderiam pensar que tal iniciativa seria para arrecadar mais impostos. Em conversa com registradores de outras comarcas, interessados na regularização dos imóveis, pode-se observar igualmente a falta de interesse político municipal, seja por desconhecimento técnico, seja por não vislumbrarem ganhos imediatos.

Foi em boa hora, portanto, que o legislador federal previu e regulamentou mais um instrumento para viabilizar, na prática, a implementação da regularização fundiária: a usucapião extrajudicial, incluída no art. 1071 do novo Código de Processo Civil, Lei no 13.105 de 16 de março de 2015.

\section{1 - A previsão da usucapião extrajudicial no novo Código de Processo Civil}

O legislador federal deu mais um passo decisivo e importantíssimo no sentido de conferir, diretamente, a titularidade da propriedade aos ocupantes de imóveis, regulares ou irregulares, que se encontram em situação de posse consolidada, com a inclusão da chamada usucapião extrajudicial no novo Código de Processo Civil, recentemente sancionado pela Presidente da República, Lei $n^{\circ} 13.105$ de 16 de março de 2015, em seu art. 1071, que só entrará em vigor em 17 de março de 2016.

O art. 1.071 do novo Código de Processo Civil acrescentou ao Capítulo III do Título V da Lei no 6.015, de 31 de dezembro de 1973, Lei de Registros Públicos, o art. 216-A, que terá a seguinte redação:

Sem prejuízo da via jurisdicional, é admitido o pedido de reconhecimento extrajudicial de usucapião, que será processado diretamente perante o cartório do registro de imóveis da comarca em que estiver situado o imóvel usucapiendo, a requerimento do interessado, representado por advogado, instruído com: I - ata

\footnotetext{
${ }^{3}$ No dia 11 de março de 2015, foi realizada uma reunião entre Prefeitos e membros das prefeituras municipais, com o Promotor de Justiça da Comarca, e a titular da Serventia de Registro de Imóveis em que se chegou a um cronograma simplificado das fases de implementação da regularização fundiária, para dar início efetivamente à sua aplicação nos Municípios da Comarca de São João da Ponte. A ata da reunião foi firmada por todos os presentes, sem que, no entanto, tenha sido dado andamento ao processo de regularização.
} 
notarial lavrada pelo tabelião, atestando o tempo de posse do requerente e seus antecessores, conforme $\mathrm{o}$ caso e suas circunstâncias; II - planta e memorial descritivo assinado por profissional legalmente habilitado, com prova de anotação de responsabilidade técnica no respectivo conselho de fiscalização profissional, e pelos titulares de direitos reais e de outros direitos registrados ou averbados na matrícula do imóvel usucapiendo e na matrícula dos imóveis confinantes; III - certidões negativas dos distribuidores da comarca da situação do imóvel e do domicílio do requerente; IV - justo título ou quaisquer outros documentos que demonstrem a origem, a continuidade, a natureza e o tempo da posse, tais como o pagamento dos impostos e das taxas que incidirem sobre o imóvel.

Os parágrafos do art. 1071 da Lei n. 13.105/15, por sua vez, disciplinam o rito a ser observado para aplicação da usucapião, de modo a concentrar todos os atos procedimentais nas próprias Serventias extrajudiciais, tanto nos Registros de Imóveis que ficarão responsáveis, entre outros atos, pela análise dos documentos apresentados e pela notificação dos confrontantes, órgãos públicos, municipais, estaduais e federais, como pelos Tabelionatos de Notas que serão incumbidos da elaboração da ata notarial que atestará os requisitos necessários para configurar a usucapião ${ }^{4}$.

A Lei n. $13.105 / 15$, por meio da usucapião extrajudicial, permitirá que o próprio possuidor requeira diretamente ao Cartório de Registro de Imóveis a regularização de seu

\footnotetext{
${ }^{4}$ Os parágrafos do art. 1071 da Lei n. 13.105/15 assim dispõem: "§ $1^{\circ}$ O pedido será autuado pelo registrador, prorrogando-se o prazo da prenotação até o acolhimento ou a rejeição do pedido. $\S 2^{\circ}$ Se a planta não contiver a assinatura de qualquer um dos titulares de direitos reais e de outros direitos registrados ou averbados na matrícula do imóvel usucapiendo e na matrícula dos imóveis confinantes, esse será notificado pelo registrador competente, pessoalmente ou pelo correio com aviso de recebimento, para manifestar seu consentimento expresso em 15 (quinze) dias, interpretado o seu silêncio como discordância. $\S 3^{\circ} \mathrm{O}$ oficial de registro de imóveis dará ciência à União, ao Estado, ao Distrito Federal e ao Município, pessoalmente, por intermédio do oficial de registro de títulos e documentos, ou pelo correio com aviso de recebimento, para que se manifestem, em 15 (quinze) dias, sobre o pedido. $\S 4^{\circ} \mathrm{O}$ oficial de registro de imóveis promoverá a publicação de edital em jornal de grande circulação, onde houver, para a ciência de terceiros eventualmente interessados, que poderão se manifestar em 15 (quinze) dias. § 5- Para a elucidação de qualquer ponto de dúvida, poderão ser solicitadas ou realizadas diligências pelo oficial de registro de imóveis. $\S 6^{\circ}$ Transcorrido o prazo de que trata o $\S 4^{\circ}$ deste artigo, sem pendência de diligências na forma do $\S 5^{\circ}$ deste artigo e achando-se em ordem a documentação, com inclusão da concordância expressa dos titulares de direitos reais e de outros direitos registrados ou averbados na matrícula do imóvel usucapiendo e na matrícula dos imóveis confinantes, o oficial de registro de imóveis registrará a aquisição do imóvel com as descrições apresentadas, sendo permitida a abertura de matrícula, se for o caso. $\S 7^{\circ}$ Em qualquer caso, é lícito ao interessado suscitar o procedimento de dúvida, nos termos desta Lei. $\S$ $8^{\text {o }}$ Ao final das diligências, se a documentação não estiver em ordem, o oficial de registro de imóveis rejeitará o pedido. § 9- A rejeição do pedido extrajudicial não impede o ajuizamento de ação de usucapião. $\S 10$. Em caso de impugnação do pedido de reconhecimento extrajudicial de usucapião, apresentada por qualquer um dos titulares de direito reais e de outros direitos registrados ou averbados na matrícula do imóvel usucapiendo e na matrícula dos imóveis confinantes, por algum dos entes públicos ou por algum terceiro interessado, o oficial de registro de imóveis remeterá os autos ao juízo competente da comarca da situação do imóvel, cabendo ao requerente emendar a petição inicial para adequá-la ao procedimento comum”.
} 
imóvel. Isso facilitará o procedimento de regularização fundiária sob dois aspectos: os possuidores de imóveis não mais dependerão da atuação das Prefeituras no que diz respeito à situação individualizada de cada um, o que, por outro lado e, por conseguinte, reduzirá consideravelmente os custos com o trabalho de demarcação.

Cada possuidor poderá medir o seu próprio lote ou terreno a fim de dar início, na Serventia de Registro de Imóveis, ao procedimento de usucapião de seu imóvel. A medição dos lotes individualmente considerados deverá ser instruída com planta, memorial descritivo, ART do engenheiro responsável e também das declarações de anuência dos confrontantes e da Prefeitura Municipal, similar ao que já ocorre no procedimento de retificação de área urbana ou rural (art. 213, inciso I, letra g, da Lei n. 6.015/73). Com essa medição, cada lote será singularizado, viabilizando a abertura de matrícula própria.

Como se pode observar, a usucapião extrajudicial, além de reduzir a complexidade do instituto da regularização fundiária tal como previsto na Lei do Programa Minha Casa, Minha Vida, também contribuirá significativamente para a redução dos custos operacionais, principalmente no que se refere às despesas pelo Poder Público, com medição de cada um dos terrenos ou lotes a serem regularizados.

Eliminando-se os custos com a medição dos lotes singularmente considerados, será possível empregar os recursos arrecadados e destinados à regularização fundiária à realização de melhorias de equipamentos urbanísticos. Uma vez delimitada a área a ser regularizada, será possível identificar eventuais carências de equipamentos de urbanização, possibilitando-se, assim, efetivas melhorias nas moradias e habitações.

Além de tornar dispensável a medição dos lotes individualmente considerados, a usucapião extrajudicial também torna desnecessária a elaboração e aprovação de lei municipal com o objetivo de conferir ao Município, que não é proprietário da área a ser regularizada, poderes para outorgar título de legitimação de posse aos detentores dos imóveis. Pelo instituto da usucapião, o direito de propriedade decorre unicamente do fato da posse ad usucapionem que depende tão somente do reconhecimento, judicial e agora também extrajudicial, de que o possuidor/usucapiente cumpriu os seus pressupostos legais.

Desse modo, a usucapião extrajudicial poderá contribuir significativamente para a efetividade e praticidade da regularização fundiária, outorgando àqueles que se encontram na posse qualificada de imóveis o título de propriedade, sem necessidade de se passar pela 
legitimação de posse ${ }^{5}$. Daí porque a nova disciplina da usucapião merece aplausos dos aplicadores do Direito.

Se aplicada ordenadamente e com responsabilidade, a usucapião extrajudicial será de enorme valia para todos os envolvidos direta e indiretamente, a começar para os próprios Municípios, para os titulares de imóveis, para o Poder Judiciário pela considerável redução de demandas judiciais relativas à usucapião e também aos conflitos de terra, e para os advogados que participarão do procedimento extrajudicial de usucapião e que passarão a ter bens imóveis para arrolar em partilhas de inventário e divórcio. Daí porque a nova disciplina da usucapião merece aplausos dos aplicadores do Direito.

Deve-se ressaltar, outrossim, que a usucapião extrajudicial não exclui a aplicação da regularização fundiária nos moldes da Lei n. 11.977/09. Muito antes pelo contrário, na medida em que surge como mais um instrumento ou mecanismo de se atribuir titulo de propriedade aos possuidores de imóveis. É, inclusive, salutar a conjugação de instrumentos da Lei 11.977/09, tal como a demarcação urbanística, com a usucapião que tramitará nas Serventias extrajudiciais. Sob esse aspecto, os Municípios poderão contribuir significativamente no trabalho de identificação e demarcação das áreas ou bairros que dependem de regularização, instituindo programas urbanísticos. Além desse trabalho, nos bairros com população predominantemente de baixa renda, por exemplo, continuará sendo necessária maior atuação por parte dos Municípios no sentido de se medir cada lote e atribuir os títulos de legitimação de posse aos seus detentores ou propiciar a usucapião.

Nesse sentido, pode-se dizer que a usucapião extrajudicial vem complementar e aprimorar o procedimento de regularização fundiária concebido pela Lei do Programa Minha Casa, Minha Vida, como mais um mecanismo, simplificado e eficaz, para legalizar e titularizar os imóveis.

Por fim, não se deve deixar de mencionar que, ao transferir para os próprios possuidores de imóveis a prerrogativa de regularizarem seus imóveis, a Lei n. 13.105/15 suscita, ainda mais, a necessidade de conscientização da população quanto aos riscos da ilegalidade imobiliária e aos benefícios e vantagens, sociais e individuais, de sua formalização, conforme será analisado a seguir.

\footnotetext{
${ }^{5}$ Uma vez que o procedimento da usucapião será submetido diretamente ao Serviço de Registro de Imóveis com o auxílio de advogado a ser nomeado pelo usucapiente, ter-se-á por dispensada a etapa mais complexa prevista na Lei n. 11.977/09, na maioria dos casos, que consistia exatamente na outorga pelo Poder Municipal dos títulos aos detentores dos imóveis que depende de prévia elaboração e aprovação de lei municipal.
} 


\section{2 - A necessidade de conscientização da população}

Apesar de ser vista com bons olhos pela população em geral, a regularização dos imóveis de uma cidade se esbarra no generalizado desconhecimento de sua extrema e essencial relevância para os interesses pessoais dos cidadãos, e principalmente para o desenvolvimento do próprio Município.

Com isso, a população acaba por contribuir e até por incentivar a criação de loteamentos irregulares, em completo e total desrespeito aos preceitos legais que impõem aos loteadores a obrigação e a responsabilidade de suprir os loteamentos com infraestrutura básica de urbanização. Inclusive pessoas, principalmente as de baixa renda, chegam a ser ludibriadas, às vezes, com falsas informações sobre a regularidade dos imóveis situados nos Municípios (isso ocorreu algumas vezes na Comarca de São João da Ponte). Desse modo, as pessoas acabam por adquirir lotes ou até casas residenciais sem a prévia ciência da efetiva situação do imóvel no Cartório de Registro de Imóveis.

Aliás, como bem ressaltado por Maria do Carmo de Rezende Campos Couto, a população considerada de média ou alta renda também revela, em geral, total falta de discernimento a respeito da necessidade de se adquirir imóveis regularizados:

O direito à regularização não pode estar restrito à camada da população de renda mais baixa. Também o cidadão de renda média ou alta que, por falta de cautela ou desconhecimento, acabou por adquirir lote em parcelamento irregular ou clandestino tem direito a ver sua situação regularizada e ver seu direito de propriedade protegido. $\mathrm{O}$ fato de alguém possuir renda acima daquela que o enquadra como de baixa renda não é sinônimo de que possui o discernimento necessário para entender que o imóvel que adquiriu não está regularizado. (2012, p. 55)

Por não ter conhecimento de que é preciso exigir o respectivo registro antes de adquirir determinado imóvel, as pessoas acabam por fomentar o mau e generalizado costume local de se adquirir lote, casa residencial ou comercial, e até áreas rurais, por meros contratos de cessão de direito, inclusive sem o devido formal de partilha, em caso de morte do antigo proprietário do imóvel.

Esse costume generalizado de se comprar imóveis por cessão de direito cria situações prejudiciais a todos os envolvidos, tais como:

a) o incentivo à criação de loteamentos irregulares, sem que o loteador tenha a mínima preocupação em respeitar os dispositivos legais que lhe impõem a responsabilidade 
pela infraestrutura de urbanização de seu empreendimento, o que acaba por transferir para o Município os gastos com a efetiva instalação dos equipamentos urbanos, de modo a suprir a falta de tal infraestrutura;

b) a insegurança para os adquirentes de imóveis nos Municípios que correm sérios riscos de perder todo o investimento aplicado na compra de imóveis irregulares, o que pode inclusive vir a gerar conflitos judiciais.

A despeito da falta de compreensão propriamente dita quanto à efetiva utilidade $\mathrm{e}$ necessidade de se exigir previamente o registro do imóvel, muitas pessoas procuram a Serventia de Registro de Imóveis com a intenção de regularizar seus documentos. Porém, outras pessoas preferem adquirir imóveis irregulares atraídas por descontos nos valores negociados e confiantes em futura intervenção do poder público para resolver a situação.

Observando-se o costume de se adquirir imóveis irregulares, principalmente lotes oriundos de loteamentos clandestinos na Comarca de São João da Ponte, é possível concluir que um dos maiores obstáculos à concretização da meta de legalização dos imóveis é exatamente a falta de conhecimento da população em geral, sobre a importância da regularização fundiária. Sem a conscientização da população, corre-se o risco de a cultura do informalismo persistir, a despeito de todos os esforços no sentido de se regularizar os imóveis dos Municípios.

Para tanto, são necessárias audiências públicas e campanhas educativas com o objetivo de informarem aos cidadãos o potencial transformador, social e econômico, da regularização fundiária, na medida em que ela viabiliza a implementação de políticas de melhorias na infraestrutura urbana e também de acesso ao crédito aos cidadãos, como se passa a demonstrar.

\section{4 - O POTENCIAL TRANSFORMADOR DA REGULARIZAÇÃO FUNDIÁRIA}

Por ser, estrita e umbilicalmente, vinculada ao direito fundamental da moradia, ao pleno desenvolvimento das funções sociais da propriedade urbana e ao direito ao meio ambiente ecologicamente equilibrado, a regularização fundiária destaca-se como importante instrumento urbanístico, social e econômico.

No presente artigo, serão objeto de análise mais detidamente apenas dois aspectos relevantes da regularização fundiária, enquanto instrumento urbanístico e fomentador de políticas de acesso ao crédito. 


\section{1 - A regularização fundiária como instrumento urbanístico}

Num primeiro momento, a regularização se destaca como importante instrumento de identificação dos problemas urbanos. Isso é possível por meio da demarcação urbanística previsto pelo art. 47 e definido como "a delimitação de uma área ocupada para fins habitacionais, de domínio público ou privado, por meio da identificação de seus limites, confrontantes, área de superfície e localização, para a realização de procedimentos de regularização fundiária de interesse social”, conforme Cartilha sobre Regularização Fundiária Urbana - Como aplicar a Lei Federal no 11.977/2009 - elaborada pela Secretaria Nacional de Habitação do Ministério das Cidades..

A demarcação urbanística, ao delimitar as áreas irregulares e clandestinas, possibilita o conhecimento de suas reais dimensões e dos problemas estruturais decorrentes da falta de equipamentos de infraestrutura urbana, tais como esgoto sanitário, energia elétrica e asfalto entre tantos outros.

Não se pode falar em implementar políticas urbanas, sem a prévia delimitação ou mapeamento das cidades. Somente após a identificação dos problemas estruturais e das áreas que exigem atuação pública, torna-se possível estabelecer metas de política urbana, viabilizando soluções concretas. Nesse contexto, é que "a regularização fundiária (...) deve ser compreendida como uma solução integrada para as questões de degradação ambiental e social, de situações de risco e de falta ou precariedade de infraestrutura, de sistema viário e de áreas públicas", também conforme Cartilha da Secretaria Nacional de Habitação do Ministério das Cidades. Isto porque a partir da delimitação das áreas irregulares, passa ser viável o planejamento para se desenvolver ordenadamente a cidade.

Por meio do mapeamento, é possível ainda identificar áreas loteadas clandestinamente, sem prévia aprovação e autorização da Prefeitura Municipal. Sob esse aspecto, a Lei Minha Casa, Minha Vida deve ser aplicada conjuntamente com a Lei ${ }^{\circ} 6.766$ de 19 de dezembro de 1979 que dispõe sobre o parcelamento do solo urbano e dá outras providências.

A Lei do Parcelamento do Solo impõe aos loteadores a responsabilidade pela infraestrutura de urbanização do empreendimento, o que nem sempre se verifica na prática. Loteamentos são criados com aberturas de lotes e posteriormente vendidos sem qualquer preocupação em cumprir as exigências legais mínimas de infraestrutura. Essa ilegalidade acaba por transferir para o Município os altos gastos com a efetiva instalação de 
equipamentos urbanos básicos, como a pavimentação das ruas por exemplo, de modo a suprir a falta de infraestrutura do empreendimento particular.

Além da demarcação física dos bairros e áreas irregulares dos Municípios, também se faz necessária a realização de uma espécie de mapeamento jurídico, promovendo-se buscas junto à Serventia de Registro de Imóveis das possíveis matrículas dos imóveis ocupados. Essa pesquisa é importante para que possa ser identificada eventual existência de titularidade das áreas a serem regularizadas, se são particulares ou se, ao contrário, pertencem ao Município ou a outro ente público ${ }^{6}$. Daí sobressai a relevância da efetiva participação das Serventias de Registro de Imóveis no procedimento de regularização fundiária, que podem inclusive ajudar na identificação das áreas ou bairros irregulares.

Em São João da Ponte, o Promotor de Justiça procurou se informar a respeito dos loteamentos irregulares com as titulares da Serventia de Registro de Imóveis e do Tabelionato de Notas para dar início a um amplo trabalho com o objetivo de unir esforços para exigir dos loteadores o cumprimento de suas obrigações legais. Com tal desiderato, o promotor reuniu-se com cada um dos loteadores, para discutir os problemas referentes à legalização dos empreendimentos e apontar soluções.

Assim é que a Promotoria de Justiça vem firmando Termos de Ajustamento de Conduta com os loteadores irregulares com o objetivo de, a um só tempo, exigir o cumprimento da lei de parcelamento do solo e, ao mesmo tempo, auxiliá-los nesse mister. Recentemente, já foram levados a registro dois loteamentos que se encontravam em situação irregular com um total de quatrocentos e trinta lotes. Outros quatro loteamentos estão em processo de regularização por seus loteadores, devido aos Termos de Conduta firmados com a Promotoria de Justiça.

\section{2 - A Regularização fundiária como instrumento de inclusão social - o acesso ao crédito}

Como dito anteriormente, na esfera individual, a regularização fundiária confere titularidade ao detentor do imóvel, quer pelo título de legitimação de posse conforme previsão da Lei n. 11.977/09, quer pela própria propriedade por força da usucapião extrajudicial recentemente disciplinada pelo novo Código de Processo Civil - Lei n. 13.105/15.

\footnotetext{
${ }^{6}$ Como a Serventia de Registro de Imóveis de São João da Ponte não disponibiliza de amplo acervo de Indicadores Reais, só é possível, em muitos casos, localizar a matrículas de certas áreas ou terrenos por meio de eventuais documentos ou certidões antigas que são obtidas junto aos cidadãos com interesse em participar do programa de regularização.
} 
Com o registro do título de legitimação de posse ou do título de usucapião na Serventia de Registro de Imóveis, o detentor do imóvel regulariza e formaliza seu imóvel, passando a estar apto a obter, junto às instituições financeiras, financiamentos de crédito com juros mais baixos e com prazos e condições mais favoráveis.

Em Municípios, cuja economia se resume à atividade agrícola e as folhas de pagamento decorrem, sobretudo, de recursos advindos das Prefeituras, a impossibilidade de acesso a crédito com juros baixos representa forte entrave ao desenvolvimento econômico e social da população. A escassez de recursos financeiros circulando nos Municípios prejudica todos os setores, principalmente o comércio local, dificultando a própria aquisição de imóveis ou o uso de recursos financeiros para outros fins, como construção ou reforma de habitações, o empreendedorismo ou o aprimoramento da atividade agrícola e pecuária.

Não é por outro motivo que políticas de ampliação do acesso ao crédito, principalmente à população de baixa renda, têm sido objeto de inúmeros estudos e pesquisas no mundo todo. Após a bem sucedida experiência do Banco Grameen em Bangladesh, cujo fundador, o professor de economia Muhammad Yunus, foi laureado com o Prêmio Nobel da Paz em 2006, instituindo o chamado microcrédito à população de baixa renda, políticas de acesso ao crédito, pertinentes mais especificamente ao microcrédito, passaram a ser desenvolvidas e implementadas em diversos países. A criação do microcrédito, "compreendido como a concessão de crédito de baixo valor, destinado a micro e pequenos empreendimentos, geralmente informais, porém com alto potencial, produtivo e com a finalidade de alavancar as atividades iniciais", teve por objetivo contribuir para a superação da pobreza" (ALICE, RUPPENTHAL, 2012, p. 23-34).

Diversas pesquisas apontam que a distribuição igualitária do crédito constitui importante ferramenta para a superação da pobreza, na medida em que viabiliza novos empreendimentos e novas alternativas ocupacionais, aquecendo a economia e possibilitando o desenvolvimento da sociedade, conforme observado por LEANDRO ALICE e JANIS ELISA RUPPENTHTAL:

A distribuição igualitária do crédito é certamente a ação mais viável para enfrentar a moderna dinâmica das economias. $\mathrm{O}$ acesso ao crédito da população de baixa renda, segundo Santos (2007), é uma das funções propulsoras ao surgimento de alternativas ocupacionais, aumento de produtividade, viabilização de novos empreendimentos e, consequentemente, o aquecimento da economia que possibilita o desenvolvimento da sociedade. Dessa forma, o instrumento de microcrédito passa a ser uma importante alternativa no combate à pobreza e à exclusão social. (2012, p. 23$34)$. 
Também neste contexto, PAULO SOARES SAMPAIO destaca que o acesso ao crédito à população de baixa renda consubstancia instrumento propulsor do empreendedorismo e também representa via alternativa no combate à pobreza e à exclusão social:

No sistema financeiro tradicional, buscou-se contextualizar a concessão de crédito para a população de baixa renda, visando desenvolver o empreendedorismo como propulsor do surgimento de alternativas ocupacionais. Evidencia-se que a distribuição igualitária do crédito, mediante um sistema financeiro dinâmico, é preconizar o crescimento e desenvolvimento econômicos. Nesse sentido, o microcrédito pode ser um instrumento de amplo alcance às comunidades mais pobres, na promoção de mudanças sociais $(2014 \text {, p. } 120)^{7}$.

No Brasil, políticas de acesso ao microcrédito também foram implementadas, como registram LEANDRO ALICE e JANIS ELISA RUPPENTHTAL:

No Brasil, os primeiros ensaios com o microcrédito chegaram, ainda, nas décadas de 70/80, com a característica principal de constituir uma rede de ONGs, para a concessão de financiamentos a pequenos negócios, voltados ao setor urbano informal. O propósito inicial era de se ofertar às populações mais pobres, oportunidades de financiamento às atividades produtivas. Assim como em outros países da América Latina, no Brasil, as ONGs também, foram pioneiras ao introduzir metodologias de microfinanças. $(2012, \text { p. } 30)^{8}$

\footnotetext{
7 Ainda sobre a relevância social e econômica do microcrédito Paulo Soares Sampaio registra que: "O microcrédito contribui não somente para a superação da pobreza, mas para a emancipação política, em sentido contrário ao paternalismo, proporcionando a seus financiados a conjugação de capital humano e capital monetário para a melhoria das condições de vida. Conjugando a melhoria das condições de vida com o empoderamento e com a emancipação, o modelo de microcrédito proposto por Yunus e Jolis (2000) alinha-se com o conceito de desenvolvimento como liberdade proposto por Sem (2000). A inserção socieconomica dos microempreendedores pode contribuir para a expansão de suas capacidades, influenciando suas habilidades produtivas e possibilitando sua participação no processo de crescimento econômico" (2014, p. 123).

${ }^{8}$ O Professor-Adjunto do Instituto de Economia da Unicamp, Fernando Nogueira da Costa, confirma que: "No Brasil, a iniciativa apareceu, nos anos 90, com a participação do Terceiro Setor. No começo de 2002, existiam 67 OSCIP de microcrédito e 24 SCM. Além disso, com governos populares sendo eleitos para as administrações municipais e estaduais, houve a implantação de 'Bancos do Povo' para apoiar a geração de ocupação e renda" (2010, p. 11). O mencionado professor de economia esclarece a participação das instituições financeiras federais: "Entre os bancos públicos federais, a iniciativa mais antiga foi a do CrediAmigo do Banco do Nordeste (BNB), em funcionamento desde 1998. O BNB fez a opção de criar uma OSCIP, o Instituto Nordeste Cidadania, para operar diretamente o microcrédito. O Instituto fazia a análise de crédito, o assessoramento empresaria e o acompanhamento dos pagamentos, focando a região rural do semi-árido nordestino. O BNB atuava nos mesmos moldes da maioria das OSCIP voltadas ao microcrédito produtivo orientado, isto é, com grupos de aval solidário e agentes de crédito itinerantes, muitos dos quais eram agrônomos terceirizados" (2010, p. 11).
} 
Conforme constatado em estudo publicado em 2012, "mudança e avanços significativos ocorreram no Brasil, com o advento do Programa Nacional de Microcrédito Produtivo Orientado (Lei n. 11.110/05), originado pela Medida Provisória $n^{\circ}$ 226/04. As organizações de microcrédito, ao lado das cooperativas de crédito, bancos de desenvolvimento e agências de fomento, passaram a ter oportunidade de acessar recursos abundantes, tanto do Fundo de Amparo ao Trabalhador (FAT), como da parcela dos recursos de depósitos à vista, destinada ao microcrédito (Le n. 10.735/03). O Governo Federal, como a MP, buscou estabelecer condições jurídicas, para que o SEBRAE e o FUNPROGER possam ampliar seus sistemas de garantia e prestar aval em operações de crédito das instituições de microcréditos, juntamente com bancos públicos e privados (MORENO, 2005)” (ALICE, RUPPENTHAL, 2012, p. 28) ${ }^{9}$.

O microcrédito foi concebido depois que Muhammad Yunus verificou que "as barreiras no acesso ao crédito pela população de baixa renda contribuem para sua exclusão financeira e social” (SAMPAIO, 2014, p. 118). Após analisar os procedimentos normalmente adotados e seguidos pelas instituições financeiras para selecionarem os potenciais tomadores de crédito, entre eles a exigência de garantias reais, o fundador do Banco Grameen anotou as causas que levam à exclusão do segmento de baixa renda, conforme registra PAULO SOARES SAMPAIO:

O procedimento adotado pelas instituições financeiras tradicionais explica a exclusão do segmento de baixa renda do mercado de crédito bancário. Com frequência, as atividades econômicas desempenhadas por este estrato não são registradas, isto é, são informais, e não há uma contabilidade organizada que permita a análise de fluxo de caixa e de balanços patrimoniais, o que eleva a taxa de juros exigida. Não é raro que a taxa de juros necessária para cobrir o risco supere o 'teto' de juros praticados, o que leva à negativa de concessão do crédito. Como os integrantes deste segmento possuem baixa renda, frequentemente não há garantias reais a oferecer" $(2014 \text {, p. } 119 \text { e } 120)^{10}$.

\footnotetext{
${ }^{9}$ Rayssa Danielle Dantas Mayrink que estudou o microcrédito no Município de Belo Horizonte, capital do Estado de Minas Gerais, ressaltou que: "O Microcrédito tem se revelado um instrumento importante para os países emergentes menos desenvolvidos, na medida em que vem permitindo que um número expressivo de cidadãos consiga desenvolver atividades econômicas por conta própria, oferecendo ocupação para pessoas e membros de suas famílias e, até mesmo, gerar algum emprego adicional com pequenos investimentos. Atualmente o microcrédito tem sido a alternativa de acesso ao crédito para setores de baixa renda, fator essencial para a promoção do desenvolvimento individual e coletivo. $\mathrm{O}$ microcrédito tem sido analisado como uma alternativa adequada para geração de emprego e renda para os menos incluídos. Essa realidade, ainda em construção, e que se apresenta de maneira diferente em vários países, instiga o pesquisador a avaliar como se pode fornecer aos micro e pequenos empreendedores o necessário apoio monetário, creditício e administrativo, para que possam crescer econômica, social e politicamente" (2009).

${ }^{10}$ Ainda sobre a relevância social e econômica do microcrédito Paulo Soares Sampaio registra que: "O microcrédito contribui não somente para a superação da pobreza, mas para a emancipação política, em sentido contrário ao paternalismo, proporcionando a seus financiados a conjugação de capital humano e capital
} 
Tendo em vista os procedimentos tradicionalmente observados pelas instituições financeiras, PAULO SOARES SAMPAIO observou que "o mercado de crédito para o segmento de baixa renda possui uma grande demanda reprimida pela ausência de oferta, que é suprida frequentemente por agiotas, que praticam elevadas taxas de juros e utilizam práticas coercitivas para assegurar o recebimento das parcelas devidas. O segmento de mais baixa renda, desta forma, se vê excluído do acesso ao crédito bancário para a realização de seus projetos, e se torna refém de um sistema alternativo que lhe reduz ainda mais a capacidade de pagamento" (2014, p. 120).

Assim é que uma das principais dificuldades enfrentadas pela política do microcrédito concebida pelo Banco Grameen foi no sentido de suprir a inexistência de garantia real que pudesse ser oferecida pela população de baixa renda, de modo a criar alternativas para se evitar a inadimplência ${ }^{11}$. Para que o microcrédito pudesse atender a pessoas que não possuíam bem imóvel para oferecer em garantia, foram criadas alternativas, entre elas, o chamado aval solidário, concebido como forma de se garantir o adimplemento do crédito, nos seguintes moldes:

O modelo Grameen utiliza um sistema de pagamento semanal, com parcelas reduzidas, e um aval concedido por um grupo de cinco pessoas com o mesmo status socioeconômico, denominado aval solidário. O empréstimo é concedido após um treinamento aos financiados sobre o sistema, de forma sequencial: na primeira fase, são concedidos empréstimos a dois membros do grupo; após seis semanas tendo havido o pagamento semanal regular, o empréstimo é estendido a dois outros membros, e após mais seis semanas, tendo sido mantida a regularidade dos pagamentos pelos quatro membros, o empréstimo é concedido ao responsável pelo grupo. Uma parcela do empréstimo (cinco por cento) é direcionada para um fundo mútuo do grupo; além disso, em cada empréstimo, os demais membros do grupo devem depositar uma pequena quantia fixa nesse fundo. $\mathrm{O}$ não pagamento de uma parcela semanal por

monetário para a melhoria das condições de vida. Conjugando a melhoria das condições de vida com o empoderamento e com a emancipação, o modelo de microcrédito proposto por Yunus e Jolis (2000) alinha-se com o conceito de desenvolvimento como liberdade proposto por Sem (2000). A inserção socieconomica dos microempreendedores pode contribuir para a expansão de suas capacidades, influenciando suas habilidades produtivas e possibilitando sua participação no processo de crescimento econômico" (2014, p. 123).

${ }^{11}$ Leandro Alice e Janis Elisa Ruppenthal destacam que um dos objetivos da política de microcrédito do Banco Grameen "está em prestar assistência financeira à parcela da população que compõe a base da pirâmide social, que não dispõe de patrimônio e/ou rendimento suficiente para apresentar garantias reais nas operações financeiras convencionais. Esses empreendedores são, na maioria das vezes, excluídos do acesso ao crédito concedido pelas instituições financeiras tradicionais, que compõem o SFN. Nesses termos, pode-se dizer que certamente existem inúmeras inovações, mesmo que incrementais, mas que ainda não ingressaram no mercado, por falta de microcrédito" (2012, p. 23-34). 
qualquer dos membros impede o acesso a novo crédito para todo o grupo. Como as parcelas são reduzidas, os demais integrantes do grupo se cotizam para realizar o pagamento em nome do membro com dificuldades, evitando o inadimplemento (SAMPAIO, 2014, p. 121 e 122).

Em suma, todo um sistema de garantia ao pagamento do crédito foi criado como alternativa sustentável para substituir a garantia real e, desse modo, evitar a inadimplência dos tomadores do microcrédito. Assim é que o aval solidário tornou-se um dos pilares da política de microcrédito concebida por Muhammad Yunus. Porém, o modelo de garantia por grupo esbarrou em alguns percalços, como o seu alto custo operacional e a dificuldade de estabelecer vínculos entre as pessoas que pretendiam obter crédito junto às instituições, conforme esclarece PAULO SOARES SAMPAIO:

Embora o modelo criado por Yunus seja a referência mundial em microcrédito, de reconhecido sucesso em Bangladesh e outros países, a prática mostrou que o sucesso na adoção do aval solidário guarda vínculos com as características de cada sociedade. [...] Para alguns especialistas do setor, a dificuldade em estabelecer vínculos de confiança suficientes, que permitissem a um membro do grupo ser avalista dos demais, se constitui em uma barreira adicional ao sucesso da metodologia do aval solidário (2014, p. 124).

No Brasil, em particular, no que tange à garantia de pagamento baseada no aval solidário, houve "grandes dificuldades para constituir tais grupos em favelas de regiões metropolitanas", pois "era necessário muito tempo para os agentes de crédito itinerantes terem o acesso e a confiança para o acompanhamento semanal das atividades dos potenciais beneficiários e o recebimento dos pagamentos. O problema é que o custo de qualquer bancário, considerando todos os direitos trabalhistas, inviabilizava a contratação direta de 'agentes de crédito' por parte de bancos comerciais, seja público, seja privado”, como observado por Fernando Nogueira da Costa (2010, p.19 e 20).

É, nesse cenário, que a regularização dos imóveis se destaca como instrumento que viabiliza o acesso ao crédito em condições mais favoráveis a pessoas que, embora sejam consideradas de baixa renda, possuem imóvel próprio. Com a regularização fundiária que propiciará título de propriedade aos detentores dos imóveis, pode-se concluir que um dos principais entraves ao êxito do microcrédito será reduzido consideravelmente. Pessoas que residem inclusive em bairros mais humildes ou em favelas brasileiras passarão a ter título de propriedade, o que conferirá maior amplitude e segurança ao crédito. 
Destarte, a regularização fundiária pode vir a corroborar com políticas de acesso ao crédito, substituindo os avais solidários ou em grupo, na medida em que propiciará título de propriedade àqueles que se encontram em situação de posse consolidada sobre os imóveis, munindo-os de instrumento hábil que poderá ser oferecido em garantia de adimplemento do crédito a ser financiado. A política de regularização dos imóveis, portanto, desponta-se como importante ferramenta impulsionadora de políticas de acesso ao crédito e, consequentemente, de inclusão social e econômica. O que ora se propõe, portanto, é mais uma alternativa para se aprimorar, revigorar e consolidar as políticas de microcrédito e do crédito, conferindo-lhes maior sustentabilidade e credibilidade.

Isto ocorre, como bem ressaltado pelo desembargador Marcelo Rodrigues Guimarães, devido ao "relevante papel dos registros públicos na fundamentação econômica dos direitos de propriedade. Um bom sistema de registro de direitos tem mecanismos para assimilar informações imprescindíveis, como garantias reais, que assegurem a titularidade do bem" (2014, p.41).

Em sua obra Tratado de Registros Públicos e Direito Notarial, Marcelo Rodrigues esclarece em que medida um sistema registral bem estruturado contribui para o fomento de atividades econômicas no país e, em sentido inverso, quais são os riscos decorrentes de um sistema registral pautado na clandestinidade e o seu impacto negativo na economia:

Independentemente do sistema registral adotado pelo país, ele deve garantir os direitos do adquirente e dar segurança jurídica para que as transações ocorram com previsibilidade e certeza. Quando a confiança dos bancos aumenta, os juros caem e de uma maneira geral essa queda é refletida nos custos das transações. Vale dizer, mais recursos sobram para serem canalizados em atividades produtivas. A falta de um modelo de registro de imóveis absolutamente protegido gera impactos negativos no sistema econômico.

Os bancos, por exemplo, cobram juros mais altos porque um imóvel dado em garantia de um financiamento pelo atual proprietário pode ser no futuro penhorado em decorrência de obrigações tributárias de responsabilidade do ex-dono. (2014, p. 41)

Sob outro aspecto, deve-se destacar, ainda, que a regularização fundiária pode contribuir com "o dinamismo econômico que leva a aumentar a geração de empregos e ampliar a estrutura atual do mercado de trabalho", na medida em que tal dinamismo "depende de melhorar a infra-estrutura urbana, para que possibilite atrair e reter capitais" (ALICE, RUPPENTHAL, 2012, p. 23-34). 
Neste sentido, Leandro Alice e Janis Elisa Ruppenthta são veementes ao afirmarem que, para o dinamismo econômico, "são necessários ainda, investimentos e ações de reestruturação urbana, que ampliem e diversifiquem as oportunidades culturais e de lazer, reduzindo os isolamentos sócio-culturais e os níveis de violência nelas existentes. Logo, depende da dinâmica de uma participação social efetiva, de forma a implantar as bases para um desenvolvimento humano, simultaneamente ao desenvolvimento econômico" (2012, p. 23-34).

Na própria Comarca de São João da Ponte, em conversa com populares, observa-se o quão positivo e salutar se apresenta a oportunidade de se obter financiamentos, podendo ser citados alguns casos como: agricultores rurais que adquiriram trator para facilitar o manuseio da terra, ou carro para transportar a produção ou, ainda, empréstimos que propiciaram a compra de boi e vaca que geraram como fruto, já no ano seguinte, o nascimento de bezerro. Em suma, pequenos investimentos que permitem a inclusão social e econômica da população de baixa renda.

\subsection{1 - Medidas para apoiar o acesso ao crédito}

A despeito de todos seus préstimos e benefícios para o setor econômico e social, não se pode olvidar os riscos e responsabilidade que envolvem operações financeiras, principalmente aquelas relativas ao crédito garantido por imóveis. A par de seu potencial propulsor da economia e da inclusão social, deve-se registrar igualmente a preocupação com a possibilidade de se agravar o problema de moradia, se houver perda de imóveis pelos tomadores de crédito que eventualmente venham a se tornar inadimplentes.

Por isso, políticas de regularização fundiária como estímulo de acesso ao crédito devem ser acompanhadas de amplo e exaustivo trabalho de conscientização da população quanto à responsabilidade de se obter financiamentos, sob pena de se criar um problema social de moradia, ao invés de se resolver o já existente.

Neste sentido, tem-se por salutar a divulgação de campanhas educativas e audiências públicas que informem à população sobre as vantagens e benefícios de se regularizar seus imóveis, entre elas a de se obter crédito em melhores condições referentes a juros e prazos, com o intuito de se investir em atividades economicamente produtivas.

Além de campanhas educativas e audiências públicas, parcerias com instituições de ensino, públicas e privadas, e outras instituições, como Sebrae, Senac, e empresas particulares, podem ajudar na criação de políticas ou programas especiais de fomento ao 
crédito, tendo em vista a regularização fundiária, e principalmente no emprego consciente de financiamentos obtidos. Nesse contexto, portanto, pode-se dizer que a criação de planos de apoio à regularização de imóveis, tanto por instituições públicas, como privadas, para financiamento do trabalho de medição dos imóveis e melhorias das infraestruturas, com posterior trabalho de abertura de cartas de crédito especialmente para aqueles que regularizarem seus imóveis, é essencial para se eliminar a clandestinidade e a ilegalidade do sistema registral dos Municípios da Comarca de São João da Ponte.

Unindo-se esforços com criatividade, pode-se "transformar problema em oportunidade" e, então, "esse grande problema moderno - pobreza e exclusão social - pode, através do microcrédito, ser transformado em oportunidades criativas. Ideias, criatividades, ampliação da capacidade pessoal e acesso ao crédito possibilitam o surgimento do empreendedorismo, oferecendo ao indivíduo maior controle sobre seu próprio destino econômico. O microcrédito é a alavanca que proporciona esse impulso inicial" (ALICE, RUPPENTHAL, 2012, p. 32).

Conforme Yunus constatou: "no mundo há dois tipos de investidores - um grupo que tem como objetivo maximizar os lucros e outro que objetiva, mais que maximizar o lucro, fazer a diferença no mundo -, propõe que o segundo grupo seja reconhecido e ajudado a tornar-se parte do mercado, com a criação de instituições de apoio, políticas, regulamentações, normas e regras", nos termos da Cartilha do Banco do Povo Paulista.

\section{CONSIDERAÇÕES FINAIS}

A despeito de a Constituição Federal de 1988 ter incluído entre os objetivos da República Federativa do Brasil a erradicação da pobreza e da marginalização e a redução das desigualdades sociais e regionais, no que tange à regularização de imóveis, pode-se concluir que ainda existem disparidades a serem dirimidas. Foi possível chegar a essa conclusão a partir do cotejo entre dados de Serventias de Registro de Imóveis de Comarca situada na região do norte e outra localizada no leste do Estado de Minas Gerais.

Por meio de dados levantados na Serventia de Registro de Imóveis, verifica-se que a irregularidade imobiliária é bastante acentuada na Comarca de São João da Ponte. Fatores de natureza política, histórica, e cultural estão arraigados e enraizados na estrutura fundiária dos municípios que integram a Comarca. Essa generalizada irregularidade decorre da inexistência de programas municipais para se implementar medidas com o objetivo de demarcação de áreas irregulares e titularização dos possuidores de imóveis; da prática de se negociar imóveis 
por contratos de cessão de direito e da falta de conhecimento pela população, em geral, da importância de se legalizar os imóveis.

Com isso, a irregularidade e ilegalidade acabam por permear consideravelmente a estrutura imobiliária dos municípios da Comarca de São João da Ponte, gerando prejuízos econômicos e sociais, tanto para a infraestrutura urbanística das cidades, como para os cidadãos que permanecem às margens do sistema registral.

Por outro, pode-se concluir à luz da legislação brasileira, que é plenamente viável a regularização dos imóveis por meio da aplicação prática dos instrumentos jurídicos previstos na Lei n 11.977/09, principalmente com a recente regulamentação da usucapião extrajudicial pela Lei n. 13.105/15 que, em muito, contribuirá para a titularização dos imóveis. Com o advento do novo Código de Processo Civil que entrará em vigor em 2016, o procedimento para regularização dos imóveis será simplificado pela usucapião que tramitará diretamente nas Serventias extrajudiciais.

No contexto de subdesenvolvimento que caracteriza a região do norte do Estado de Minas Gerais e tomando como paradigma a Comarca de São João da Ponte, observa-se que a regularização fundiária se sobressai como importante instrumento de inclusão social e econômica, na medida em que viabiliza políticas urbanísticas e de acesso ao crédito.

Enquanto instrumento urbanístico, a regularização imobiliária permite a identificação de áreas irregulares e de problemas de infraestrutura decorrentes da falta de equipamentos urbanos. Com a demarcação urbanística prevista pela Lei n. 11.977/09, torna-se possível a implementação de políticas urbanas, de sorte a suprimir a carência de equipamentos urbanos, tais como asfalto, esgoto sanitário, energia elétrica, entre tantos outros dos quais carece grande parte das moradias situadas nos Municípios da Comarca de São João da Ponte.

Além de permitir melhorias na estrutura urbana das cidades, a regularização fundiária se notabiliza por ser ferramenta essencial a políticas de acesso ao crédito e de inclusão social e econômica. Na medida em que confere título de propriedade àqueles que se encontram em situação de posse consolidada sobre os imóveis. Com isso, os possuidores passam a estar munidos de instrumento hábil a ser oferecido em garantia para obtenção de crédito junto a instituições financeiras com juros mais baixos e maiores prazos. A regularização fundiária, desse modo, pode substituir os avais solidários ou em grupo, permitindo a concessão de crédito em condições mais favoráveis à população. Essa possibilidade faz da regularização imobiliária uma alternativa, eficiente e consistente, para se fortalecer políticas de microcrédito e de crédito, de sorte a erradicar a pobreza e a reduzir as desigualdades sociais e regionais, nos moldes aspirados pelo legislador constituinte. 


\section{REFERÊNCIAS BIBLIOGRÁFICAS}

ALICE, Leandro; RUPPENTHAL, Janis Elisa. Microcrédito como fomento ao empreendedorismo na base da pirâmide social. Universidade Federal de Santa Maria. GEPROS. Gestão da Produção, Operações e Sistemas, Ano 7, n. 1, jan-mar/2012, p. 23-34.

BRASIL. Ministério das Cidades. Regularização Fundiária Urbana: Como aplicar a Lei Federal no 11.977/2009. Brasília: Ministério das Cidades, Secretaria Nacional de Habitação e Secretaria Nacional de Programas Urbanos, 2010.

CHICUTA, Kioitsi. A Função Registral e a Atuação do Judiciário. Congresso do IRIB boletim eletrônico, BE0188 - 03 de abril de 2000. Disponível no site: <http://www.irib.org.br>. Acesso em 08 de julho de 2015.

COUTO, Maria do Carmo de Rezende Campos. Regularização Fundiária de Interesse Específico. Boletim do IRIB - Instituto de Registro Imobiliário do Brasil - em Revista, São Paulo: Abril, Edição 347, 2013.

COSTA, Fernando Nogueira da. Microcrédito no Brasil. UNICAMP/IE, n. 175, Campinas, 2010.

FERNANDES, Edésio. Direito Urbanístico e Política Urbana no Brasil: Uma Introdução. In: FERNANDES, Edésio. (Organizador). Direito Urbanístico e Política Urbana no Brasil, Belo Horizonte: Del Rey, 2000.

MAYRINK, Rayssa Danielle Dantas. O Impacto do Microcrédito sobre a Renda e o Emprego em Belo Horizonte. Belo Horizonte: Fipel, 2009. (Dissertação de Mestrado) - Faculdade de Pedro Leopoldo.

MENDONÇA, Jupira Gomes de. Plano Diretor, Gestão Urbana e Descentralização: Novos Caminhos, Novos Debates. In: FERNANDES, Edésio. (Organizador). Direito Urbanístico e Política Urbana no Brasil, Belo Horizonte: Del Rey, 2000.

PRESTES, Cristine. Insegurança jurídica eleva o fator risco dos investimentos. São Paulo, Clipping Eletrônico, 2013. Disponível em: <http://www.aasp.org.br $>$. Acesso em: $12 \mathrm{de}$ agosto de 2015.

RODRIGUES, Marcelo. Tratado de Registros Públicos e Direito Notarial. São Paulo: Editora Atlas, 2014.

Aplicativo Código de Normas dos Tabeliontaos e Registros do Estado de Minas Gerais - Provimento CGJMG 260/2014 - Comentado. Revisão V, 2015.

SAMPAIO, Paulo Soares. Microcrédito, Desenvolvimento e Superação da Pobreza: uma análise jurídica do Programa Nacional de Microcrédito Produtivo Orientado. Brasília, 2014. (Dissertação de Mestrado) - Faculdade de Direito, Universidade de Brasília. Disponível em: $<$ http://repositorio.unb.br/handle/10482/16238>. Acesso em: 08 de julho de 2015. 
SANTOS, Gilmar Ribeiro dos; SILVA, Ricardo dos Santos. Desenvolvimento regional no Norte de Minas Gerais. In: 35 ${ }^{\circ}$ Encontro Anual da ANPOCS, GT05 - Desenvolvimento em perspectiva: teorias, experiências e projetos políticos, Montes Claros/MG: UNIMONTES, Agosto de 2011.

SIMÃO, Rosycler Cristina Santos. Distribuição de Renda e Pobreza no Estado de Minas Gerais. Piracicaba, 2004. (Dissertação de Mestrado) - Escola Superior de Agricultura Luiz de Queiroz, Unidade da USP. 